\title{
ANALISIS DAN PERANCANGAN SISTEM INFORMASI MONITORING QUALITY CONTROL PRODUKSI MAKANAN PADA PT. ULTRA PRIMA ABADI
}

\author{
Rohmat Taufik $^{1)}$, Liesnaningsih' ${ }^{2)}$, Dian Kasoni' ${ }^{3)}$, Dandi Setia Aji ${ }^{4)}$ \\ 1,2,3 Fakultas Teknik Program Studi Informatika, Universitas Muhammadiyah Tangerang \\ 1,2,3 rohmat.taufiq@umt.ac.id, liesnaningsih@ft-umt.ac.id, dhekalearning@gmail.com, \\ dandi.setiaaji@ft-umt.ac.id
}

\begin{abstract}
Article history Received Sep 20, 2020 Revised Okt 3 , 2020 Accepted Nov 29, 2020

Available online Nov 30,2020

Keywords Quality Control, Defective, System, Monitoring.

PT Ultra Prima Abadi is a company that produces food. Currently, the process of monitoring quality control and defective production at PT Ultra Prima Abadi is still recorded using a paper check form that allows loss or damage. The quality control and defective reporting process takes a long time because they have to recap the checking forms one by one. To solve this problem, it is necessary to design a monitoring information system for quality control and product defective monitoring. PIECES method is used to analyze the system and the Unified Modeling Language (UML) to analyze the system design to be made. With the system design that will be made, it is hoped that it can overcome the problems faced by PT Ultra Prima Abadi related to monitoring reports of quality control and defective food production.

Keywords: Quality Control, Defective, System, Monitoring
\end{abstract}

Riwayat
Diterima 20 Sept
2020
Revisi 3 Oct,
2020
Disetujui 29 Nov
2020
Terbit 30 Nov 2020
Kata Kunci
Quality Control,
Defective, Sistem,
Monitoring

\begin{abstract}
Abstrak
PT Ultra Prima Abadi merupakan perusahaan yang memproduksi makanan. Saat ini proses monitoring quality control dan defective produksi pada PT Ultra Prima Abadi masih dicatat menggunakan form pengecekan yang berbentuk kertas sehingga memungkinkan terjadinya kehilangan atau rusak. Proses pelaporan quality control dan defective membutuhkan waktu yang lama karena harus merekap satu persatu form pengecekan. Untuk mengatasi masalah tersebut maka perlu dirancang sebuah sistem informasi monitoring quality control dan defective produk. Metode PIECES digunakan untuk menganalisa sistem dan Unified Modelling Language (UML) untuk menganalisis perancangan sistem yang akan dibuat.Dengan rancangan sistem yang akan dibuat diharapkan dapat mengatasi permasalahan yang dihadapi PT Ultra Prima Abadi terkait monitoring laporan quality control dan defective produksi makanan.
\end{abstract}

Keywords: Quality Control, Defective, Sistem, Monitoring

\section{PENDAHULUAN}

Saat ini dunia sedang memasuki era revolusi industry 4.0, dimana pada era ini hampir semua bidang industry sudah mulai dan telah menggunakan teknologi informasi sebagai alat bantu dalam mendukung kegiatan bisnis, tetapi masih banyak juga perusahaan yang belum menggunakan teknologi informasi secara optimal.

PT Ultra Prima Abadi merupakan perusahaan yang bergerak dalam bidang produksi makanan

serta memiliki misi untuk mencerahkan dan menyenangkan kehidupan pelanggan, karyawan, pemegang saham, dan masyarakat dengan menciptakan dan memenuhi kebutuhan konsumen. Perusahaan harus memproduksi produk yang berkualitas tinggiagar dapat memberikan kepuasan konsumen. Untuk tercapainya kualitas produk yang baik, quality control sangat berperan penting agar produk yang diterima konsumen memiliki kualitas yang baik.

PadaPT.Ultra Prima Abadi saat ini pencatatan pengecekan kasus kemasan dan produk makanan yang dilakukan oleh bagian quality control masih ditulis dengan menggunakan kertas berupa form pengecekan. Dalam satu hari dibagi menjadi tiga shift, jadi ada tiga bagian quality control yang melakukan pengecekan dan mencatat pada form pengecekan. Kepala bagian melakukan validasai 
tiga form pengecekan setiap hari, kemudian diberikan kepada administrasi untuk direkap pada Microsoft Excel. Pengelolaan data yang berjalan saat ini kurang optimal karena pencatatan kasus kemasan dan produk makanan masih ditulis pada form pengecekan yang berbentuk kertas sehingga rentan hilang dan rusak sehingga dapat menghambat proses monitoring terhadap quality control dan defective produksi. Berdasarkan permasalahan tersebut makaperlu adanya pengembangan sistem yang mampu mengolah dan mengendalikan data menjadi lebih baik agar memudahkan monitoring laporan quality control (Rahmayani \& Haryanto, 2018).

\section{KAJIAN LITERATUR}

\subsection{Sistem Informasi}

Sistem adalah kumpulan dari sub-sub sistem baik abstrak maupun fisik yang saling treintegrasi dan berkolaborasi untuk mencapai tujuan tertentu (Taufiq, 2018). Sistem informasi adalah kumpulan dari sub-sub sistem yang saling terintegrasi dan berkolaborasi untuk menyelesaikan masalah tertentu dengan cara mengolah data sehingga memiliki nilai tambah dan bermanfaat bagi pengguna dalam (Taufiq, Magfiroh, Yusup, \& Yulianti, 2020)

\subsection{Monitoring}

"Monitoring dapat didefinisikan sebagai suatu proses mengukur, mencatat, mengumpulkan, memproses, dan mengkomunikasikan informasi untuk membantu pengambilan keputusan manajemen proyek"(Mudjahidin \& Putra, 2010). Tujuan monitoring menurut Dunn (1994) terdiri dari kesesuaian, pemeriksaan, akuntansi dan penjelasan.

\subsection{Quality Control}

"Pengendalian kualitas adalah aktivitas keteknikan dan manajemen, yang dengan aktivitas itu kita ukur cirri-ciri kualitas produk, membandingkan dengan spesifikasi atau persyaratan dan mengambil tindakan penyehatan yang sesuai apabila ada perbedaan antara penampilan yang sebenaranya dan yang standar"(Irwan \& Haryono, 2015)

\subsection{Defective}

Defective adalah terganggunya nilai atau fungsi dari seluruh unit atau produk sehingga produk tersebut dinyatakan tidak dapat digunakan lagi atau tidak memenuhi standar kualitas produksi. Unit atau produk yang defective minimal memiliki 1 (satu) defect. Dalam satu unit produ defective bisa terdiri dari beberapa defects.

\subsection{PIECES}

"PIECES adalah metode analisis sebagai dasar untuk memperoleh pokokpokok permasalahan yang lebih spesifik"'(Taufiq, Kasoni, $\&$ Liesnaningsih, 2020). Dalam PIECES terdapat enam komponen yang dapat digunakan dalam evaluasi kepuasan penggunaan sistem informasi, yaitu:

1. Performance (Kehandalan) Kehandalan suatu sistem merupakan variabel pertama dari PIECES dimana mempunyai peran penting untuk melihat sejauh mana dan seberapa handalkah suatu sistem dalam memproses untuk menghasilkan tujuan yang diinginkan. Variabel ini dapat digunakan sebagai acuan atau pedoman dalam mengevalusasi sistem dengan memperhatikan 2 komponen berikut:

a. Kemampuan suatu sistem dalam mengerjakan sejumlah perintah dalan periode waktu yang telah ditentukan, dengan baik dan tanpa hambatan (error).

b. Cepat atau lambatnya kemampuan sistem dalam merenspon suatu perintah atau program pembatasan ataupun permintaan terhadap suatu transaksi.

2. Information (Informasi) Informasi merupakan komoditas krusial bagi pengguna akhir. Evaluasi terhadap kemampuan sistem informasi dalam menghasilkan informasi yang bermanfaat perlu dilakukan untuk menyikapi dan menangani masalah yang muncul. Dalam hal ini meningkatkan kualitas informasi tidak dengan mudah menambah jumlah informasi, karena terlalu banyak informasi malah akan menimbulkan masalah baru.

3. Economic (Ekonomi) Alasan Ekonomi barangkali merupakan motivasi paling umum bagi suatu proyek. Pijakan bagi kebanyakan manajer adalah biaya atau rupiah. Persoalan ekonomis dan peluang berkaitan dengan masalah biaya.

4. Control (Kendali) Tugas-tugas bisnis perlu dimonitor dan dibetulkan jika ditemukan kinerja yang dibawah standar. Kontrol dipasang untuk meningkatkan kinerja sistem, mencegah, atau mendeteksi kesalahaan sistem, menjamin keamanan data, dan persyaratan.

5. Eficiency (Efsiensi) menyangkut bagiamana menghasilkan output sebanyak-banyaknya dengan input yang sekecil mungkin. Adapun indikasi suatu sistem dapat dikatakan efisien sebagai berikut:

a. Banyak waktu yang terbuang pada aktivitas sumber daya manusia, mesin, atau komputer.

b. Data dimasukan atau disalin secara berlebihan.

c. Informasi dihasilkan secara berlebihan.

d. Data diproses secara berlebihan. 
e. Usaha yang dibutuhkan untuk tugas-tugas terlalu berlebihan.

f. Material yang dibutuhkan untuk tugas-tugas terlalu berlebihan.

6. Service (Pelayanan) Kualitas pelayanan suatu sistem dapat dikatan buruk apabila termasuk dalam kriteria berikut:

a. Sistem menghasilkan produk yang tidak akurat

b. Sistem menghasilkan produk yang tidak konsisten

c. Sistem menghasilkan produk yang tidak dipercaya

d. Sistem tidak mudah digunakan

e. Sistem tidak fleksibel

\section{METODE PENELITIAN}

\subsection{Metode Pengumpulan Data}

Metode pengumpulan data pada penelitian ini terdiri dari observasi, wawancara dan studi pustaka, berikut penjelasannya:

1. Observasi

Observasi dilakukan dengan cara mengamati proses pengecekan markem dan kondisi kemasan mesin packing dan laporan rekap kemasan kasus packing.

2. Wawancara

Wawancara dilakukan secara langsung kepada Section Manager QC yaitu Ibu Putri Natya E. N dan Supervisi QC yaitu Ibu Rospita Mariance Sirait mengenai pengecekan proses pembuatan laporan QC.

3. Studi Pustaka

Studi pustaka dilakukan untuk mempelajari literatur terkait dengan permasalahan yang diteliti. Referensi yang penulis gunakan didapatkan dari buku dan jurnal ilmiah.

\subsection{Metode Analisa Sistem}

Metode PIECES (Performance, Information, Economy, Control, Eficiency) digunakan untuk menganalisa sistem yang saat ini berjalan.Berikut adalah hasil analisa yang penulis lakukan:

Tabel 1. Analisa PIECES

\begin{tabular}{|l|l|l|}
\hline \multicolumn{1}{|c|}{ Analisis } & Sistem Lama & Sistem Baru \\
\hline Analisis & Bagian QC & Bagian QC \\
Kinerja & mencatat & dapat \\
Performance & pengecekan & menginput \\
) & kasus & kasus \\
& kemasan dan & kemasan dan \\
& produk & produk \\
& makanan & makanan \\
& pada form & pada sistem, \\
& pengecekan & sehingga \\
& yang berupa & admin tidak \\
& kertas, & perlu \\
& kemudian & merekap ke \\
& direkap oleh & Microsoft \\
& admin pada & Excel. \\
& Ms. Excel. & \\
\hline
\end{tabular}

\begin{tabular}{|c|c|c|}
\hline $\begin{array}{l}\text { Analisis } \\
\text { Informasi } \\
\text { (Information) }\end{array}$ & $\begin{array}{l}\text { Informasi } \\
\text { kasus } \\
\text { kemasan dan } \\
\text { produk } \\
\text { makanan } \\
\text { terkadang } \\
\text { tidak lengkap } \\
\text { karena } \\
\text { hilang/rusak. }\end{array}$ & $\begin{array}{l}\text { Informasi } \\
\text { kasus } \\
\text { kemasan } \\
\text { dapat } \\
\text { langsung } \\
\text { diinput oleh } \\
\text { bagian QC } \\
\text { pada saat } \\
\text { melakukan } \\
\text { pengecekan }\end{array}$ \\
\hline $\begin{array}{l}\text { Analisis } \\
\text { Ekonomi } \\
\text { (Economy) }\end{array}$ & $\begin{array}{l}\text { Form } \\
\text { pengecekan } \\
\text { berupa kertas } \\
\text { sehingga } \\
\text { memerlukan } \\
\text { biaya untuk } \\
\text { mencetak } \\
\text { form } \\
\text { pengecekan. }\end{array}$ & $\begin{array}{l}\text { Tidak perlu } \\
\text { mengeluarka } \\
\mathrm{n} \text { biaya cetak } \\
\text { form } \\
\text { pengecekan }\end{array}$ \\
\hline $\begin{array}{l}\text { Analisis } \\
\text { Pengendalian } \\
(\text { Control })\end{array}$ & $\begin{array}{l}\text { Keamanan } \\
\text { data kasus } \\
\text { kemasan dan } \\
\text { produk } \\
\text { makanan } \\
\text { masih kurang } \\
\text { karena rentan } \\
\text { hilang/rusak }\end{array}$ & $\begin{array}{l}\text { Data kasus } \\
\text { kemasan } \\
\text { disimpan } \\
\text { dalam basis } \\
\text { data sehingga } \\
\text { lebih aman. }\end{array}$ \\
\hline $\begin{array}{l}\text { Analisis } \\
\text { Efisiensi } \\
\text { (Eficiency) }\end{array}$ & $\begin{array}{l}\text { Data kasus } \\
\text { kemasan dan } \\
\text { produk } \\
\text { makanan } \\
\text { yang ditulis } \\
\text { pada form } \\
\text { pengaduan } \\
\text { direkap satu } \\
\text { persatu oleh } \\
\text { admin } \\
\text { sehingga } \\
\text { membutuhka } \\
\text { n waktu yang } \\
\text { lama }\end{array}$ & $\begin{array}{l}\text { proses } \\
\text { pencarian } \\
\text { data dapat } \\
\text { lebih cepat } \\
\text { diakses } \\
\text { karena data } \\
\text { disimpan } \\
\text { dalam basis } \\
\text { data }\end{array}$ \\
\hline $\begin{array}{l}\text { Analisis } \\
\text { Pelayanan } \\
\text { (Service) }\end{array}$ & $\begin{array}{l}\text { Untuk } \\
\text { melihat } \\
\text { laporan } \\
\text { Pimpinan } \\
\text { harus } \\
\text { menunggu } \\
\text { rekap data } \\
\text { kasus } \\
\text { kemasan dan } \\
\text { produk } \\
\text { makanan } \\
\text { yang } \\
\text { dilakukan } \\
\text { admin }\end{array}$ & $\begin{array}{l}\text { Pimpinan } \\
\text { dapat } \\
\text { langsung } \\
\text { melihat data } \\
\text { kasus } \\
\text { kemasan dan } \\
\text { produksi } \\
\text { makanan } \\
\text { pada sistem. }\end{array}$ \\
\hline
\end{tabular}

\section{HASIL DAN PEMBAHASAN}

Setelah melakukan analisa terhadap sistem monitoring quality control dan defective produksi yang saat ini berjalan di PT Ultra Prima Abadi, 
maka diketahui bahwa sistem yang berjalan saat ini masih belum efisien sehingga perlu adanya pengembangan sistem yang mampu mengolah data menjadi lebih baik agar memudahkan memonitoring quality control dan defective produksi makanan.

Dalam perancangan sistem yang diusulkan ini peneliti menggunakan UML (Unified Modelling Language) diagram diantaranya usecase diagram, activity diagram, dan statechart diagram.

\subsection{Usecase Diagram yang Diusulkan}

Berikut adalah usecase diagramsistem informasi monitoring quality control dan defective produksi makanan yang diusulkan:

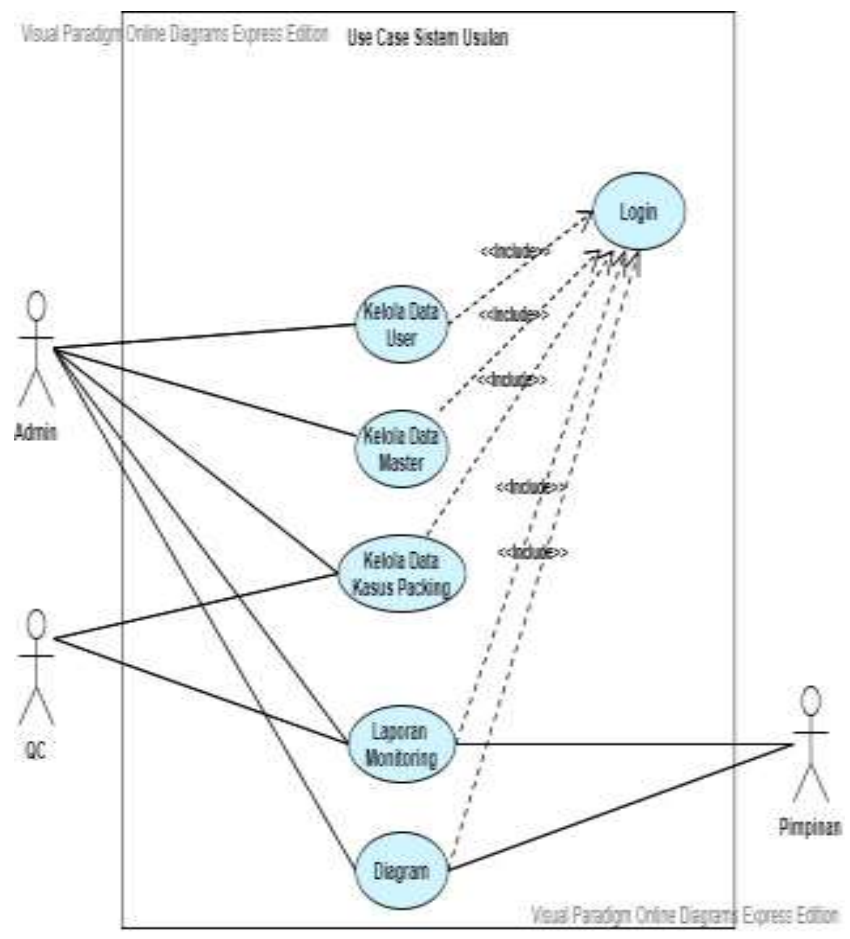

Gambar1. UseCase Diagram yang diusulkan

Berdasarkan skema diagram diatas, maka dapat dijelaskan skenario yang terjadi sebagai berikut:

1. 1 (satu) system yang mencakup semua kegiatan rancangan sistem quality control.

2. 3 (tiga) actor yang melakukan kegiatan meliputi QC, Admin, dan Pimpinan.

3. 6 (enam) use case, yang di lakukan actor yaitu: login,kelola data user, kelola data master, kelola data kasus packing, laporan monitoring, dan diagram

4. 5 (lima) include, yang terdapat pada login yaitu:kelola data user, kelola data master, kelola data kasus packing, laporan monitoring, dan diagram.

\subsection{Activity Diagram yang Diusulkan}

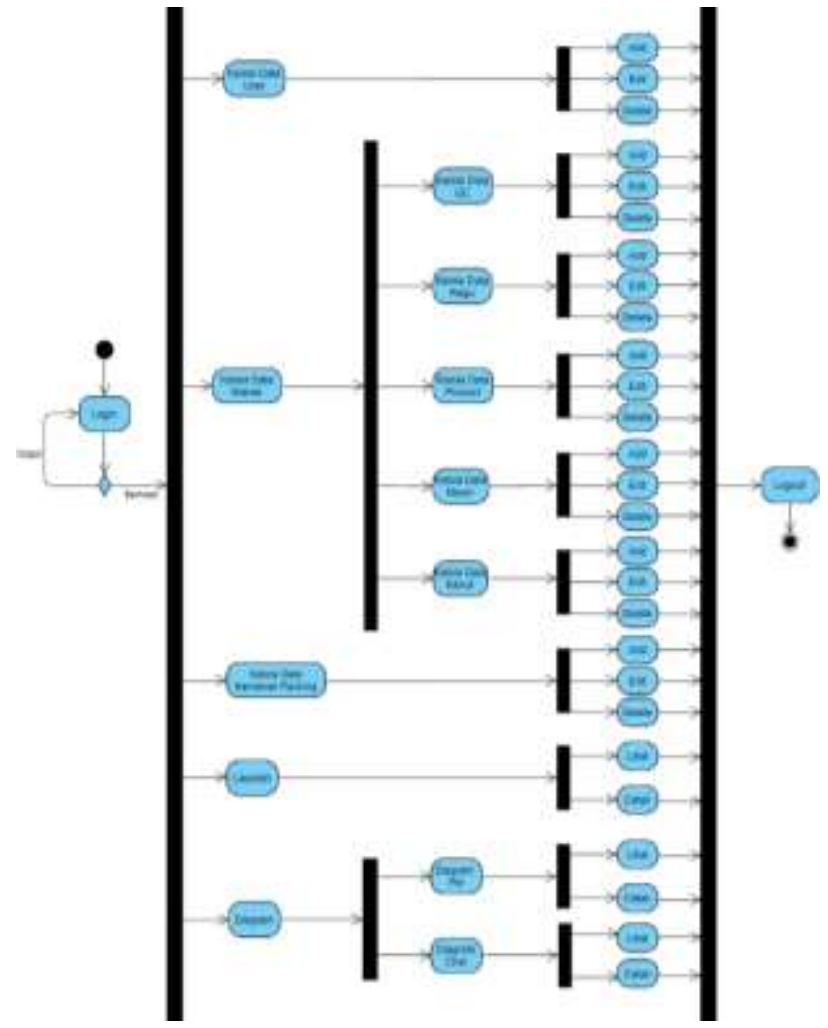

Berikut adalah activity diagram sistem informasi monitoring quality control dan defective produksi makanan yang diusulkan:

Gambar2. Activity Diagram yang diusulkan

Berdasarkan gambar Activity Diagram yang diusulkan terdapat:

1. 1 ( satu ) Initial Node, awal kegiatan.

2. 40 (Empat Puluh) Action, State dari sistem yang mencerminkan eksekusi dari suatu aksi.

3. 1 (satu) decision note sebagai suatu tindakan yang harus diambil pada kondisi tertentu.

4. 1 ( satu ) Final Node, akhir suatu kegiatan.

\subsection{Statechart Diagram yang Diusulkan}

Berikut adalah statechart diagram sistem informasi monitoring quality control dan defective produksi makanan yang diusulkan: 


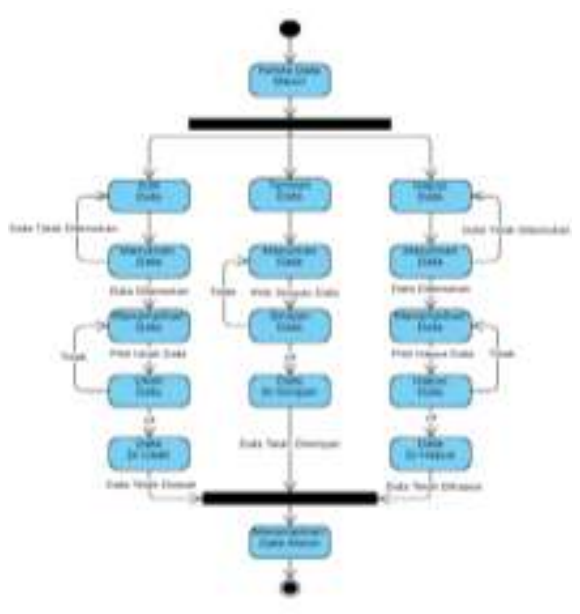

Gambar 3 Statechart Kelola Data

\subsection{Rancangan Basis Data}

Berikut adalah rancangan basis data sistem informasi monitoring quality control dan defective produk makanan yang akan dibuat:

1. Tabel User
Nama Tabel
Primary Key
Deskripsi
dan informasi user

$$
\begin{aligned}
& \text { : tabel_user } \\
& \text { : iduser } \\
& \text { : untuk menyimpan data }
\end{aligned}
$$

\begin{tabular}{|c|l|l|c|l|}
\hline No & $\begin{array}{c}\text { Nama } \\
\text { Field }\end{array}$ & Type & Ukuran & Keterangan \\
\hline 1 & iduser & Integer & 5 & Id User \\
\hline 2 & username & Varchar & 20 & Nama User \\
\hline 3 & password & Varchar & 20 & $\begin{array}{l}\text { Password } \\
\text { User }\end{array}$ \\
\hline
\end{tabular}

2. Tabel QC

Nama Tabel

Primary Key

Deskripsi

: tabel_qc

: idqc

: untuk menyimpan data

dan informasi quality control

\begin{tabular}{|c|l|l|l|l|}
\hline No & $\begin{array}{c}\text { Nama } \\
\text { Field }\end{array}$ & Type & Ukuran & Keterangan \\
\hline 1 & idqc & Integer & 5 & Id QC \\
\hline 2 & namaqc & Varchar & 20 & Nama QC \\
\hline
\end{tabular}

3. Tabel Regu
Nama Tabel
Primary Key
Deskripsi
: tabel_regu
: idregu
: untuk menyimpan data
dan informasi regu

\begin{tabular}{|c|l|l|c|l|}
\hline No & $\begin{array}{c}\text { Nama } \\
\text { Field }\end{array}$ & Type & Ukuran & Keterangan \\
\hline 1 & idregu & Integer & 5 & Id Regu \\
\hline 2 & namaregu & Varchar & 10 & $\begin{array}{l}\text { Nama } \\
\text { Regu }\end{array}$ \\
\hline
\end{tabular}

4. Tabel Produk

Nama Tabel

Primary Key

: tabel_produk

: idproduk
Deskripsi

dan informasi produk

\begin{tabular}{|c|l|c|c|l|}
\hline No & Nama Field & Type & Ukuran & Keterangan \\
\hline 1 & idproduk & Integer & 5 & Id Regu \\
\hline 2 & namaproduk & Varchar & 20 & $\begin{array}{l}\text { Nama } \\
\text { Produk }\end{array}$ \\
\hline 3 & gramasi & Varchar & 5 & $\begin{array}{l}\text { Gramasi } \\
\text { Produk }\end{array}$ \\
\hline
\end{tabular}

5. Tabel Mesin

Nama Tabel

Primary Key

Deskripsi

: tabel_mesin

dan informasi mesin

: idmesin

: untuk menyimpan data

\begin{tabular}{|c|l|c|c|l|}
\hline No & Nama Field & Type & Ukuran & Keterangan \\
\hline 1 & idmesin & Integer & 5 & Id Mesin \\
\hline 2 & nomermesin & Integer & 5 & $\begin{array}{l}\text { Nomer } \\
\text { Mesin }\end{array}$ \\
\hline 3 & namamesin & Varchar & 10 & $\begin{array}{l}\text { Nama } \\
\text { Mesin }\end{array}$ \\
\hline
\end{tabular}

6. Tabel Kasus

Nama Tabel : tabel_kasus

Primary Key : : idkasus

Deskripsi : untuk menyimpan data

dan informasi kasus

\begin{tabular}{|c|l|l|c|l|}
\hline No & Nama Field & Type & Ukuran & Keterangan \\
\hline 1 & idkasus & Integer & 5 & Id Kasus \\
\hline 2 & namakasus & Varchar & 20 & Nama Kasus \\
\hline
\end{tabular}

7. Tabel Kasus Kemasan
Nama Tabel
: tabel_kasuskemasan
Primary Key
: idinput
Deskripsi
: untuk menyimpan data

dan informasi kasus kemasan

\begin{tabular}{|c|l|l|c|l|}
\hline No & Nama Field & Type & Ukuran & Keterangan \\
\hline 1 & idinput & Integer & 5 & Id Input \\
\hline 2 & Tanggal & Date & 15 & $\begin{array}{l}\text { Tanggal } \\
\text { Input }\end{array}$ \\
\hline 3 & idqc & Integer & 5 & Id qc \\
\hline 4 & idregu & Integer & 5 & Id regu \\
\hline 5 & idmesin & Integer & 5 & Id mesin \\
\hline 6 & idproduk & Integer & 5 & Id produk \\
\hline 7 & Idkasus & Integer & 5 & Id kasus \\
\hline 8 & jumlah & Varchar & 10 & $\begin{array}{l}\text { Jumlah } \\
\text { Kasus }\end{array}$ \\
\hline
\end{tabular}

\subsection{Rancangan Antar Muka}

Berikut adalah rancangan antar muka sistem informasi monitoring quality control dan defective produk makanan:

1. Tampilan Login 


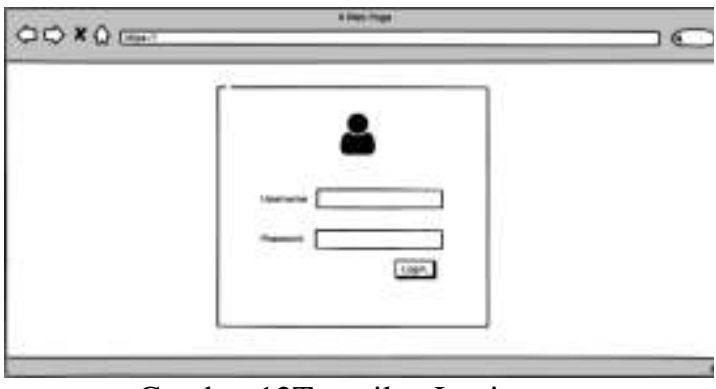

Gambar 12Tampilan Login

2. Tampilan Kelola Data User

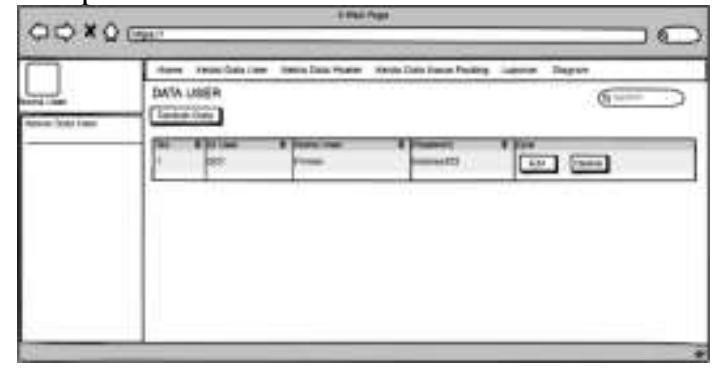

Gambar 13Tampilan Kelola Data User

3. Tampilan Kelola Data Master

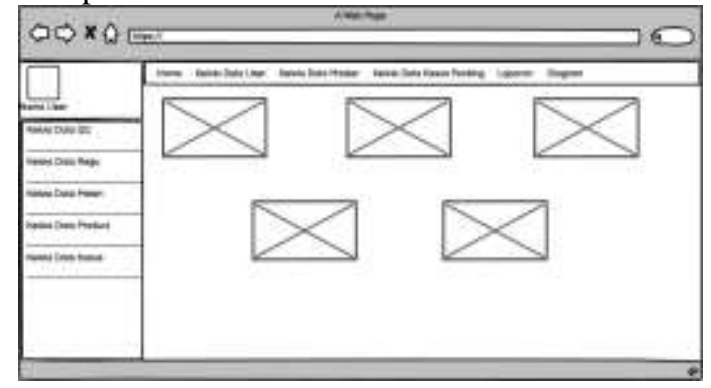

Gambar 14Tampilan Kelola Data Master

4. Tampilan Kelola Data QC

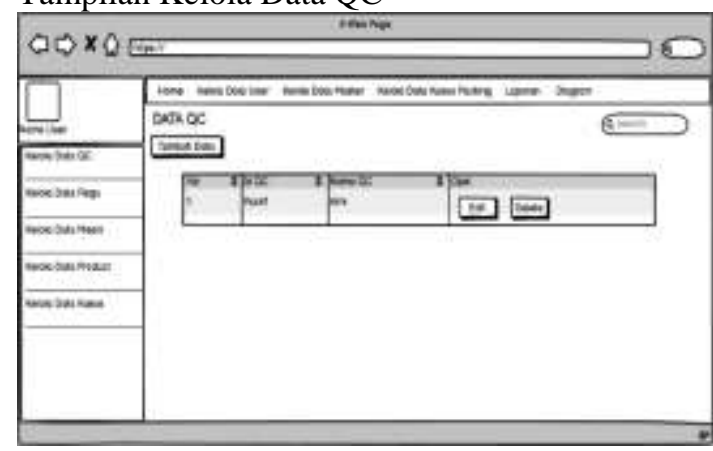

Gambar 15Tampilan Kelola Data QC

5. Tampilan Kelola Data Regu

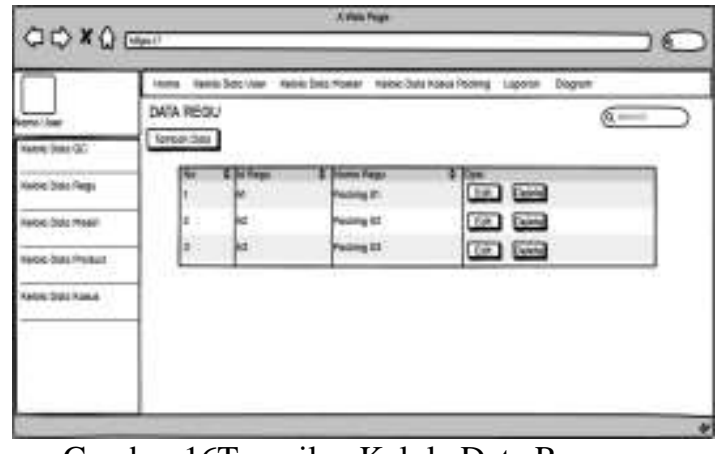

Gambar 16Tampilan Kelola Data Regu

6. Tampilan Kelola Data Mesin

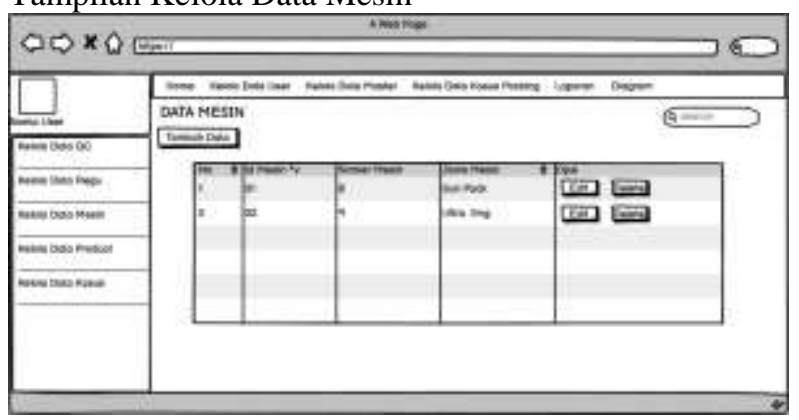

Gambar 16Tampilan Kelola Data Mesin

7. Tampilan Kelola Data Product

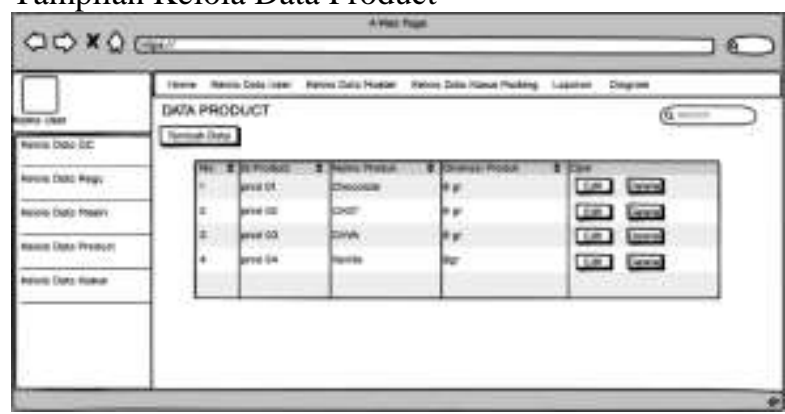

Gambar 17Tampilan Kelola Data Product

8. Tampilan Kelola Data Kasus

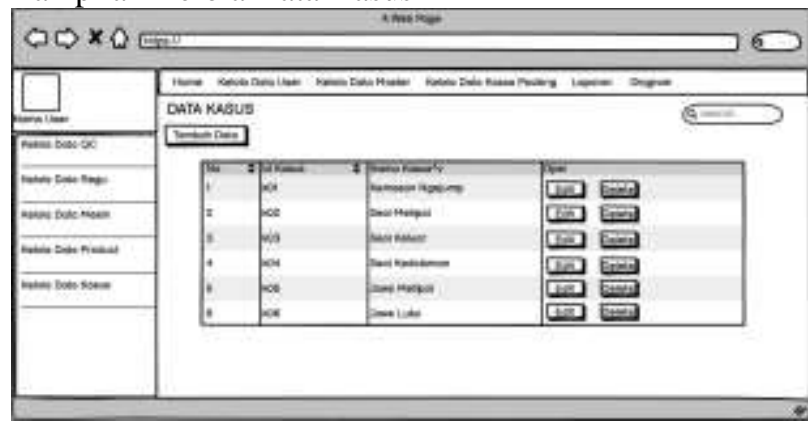

Gambar 18Tampilan Kelola Data Kasus 
9. Tampilan Kelola Data Kasus Kemasan

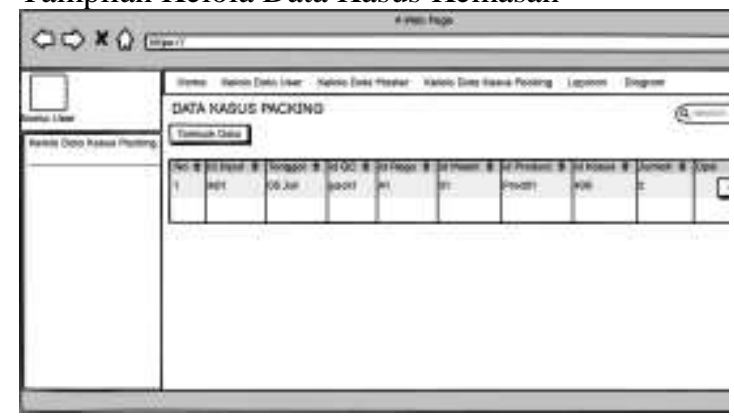

Gambar 19Tampilan Kelola Data Kasus Kemasan

10. Tampilan Laporan

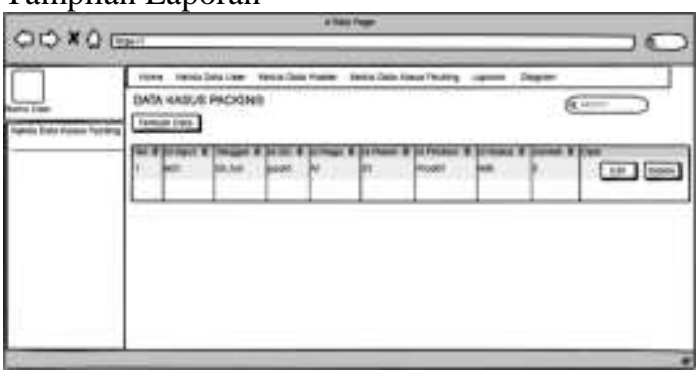

Gambar 20 Tampilan laporan

11. Tampilan Diagram

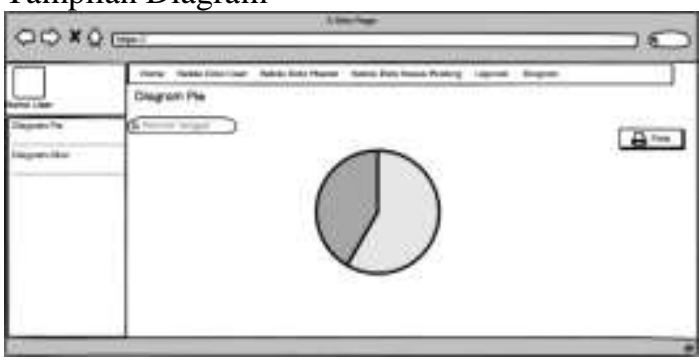

Gambar 19Tampilan Diagram Pie

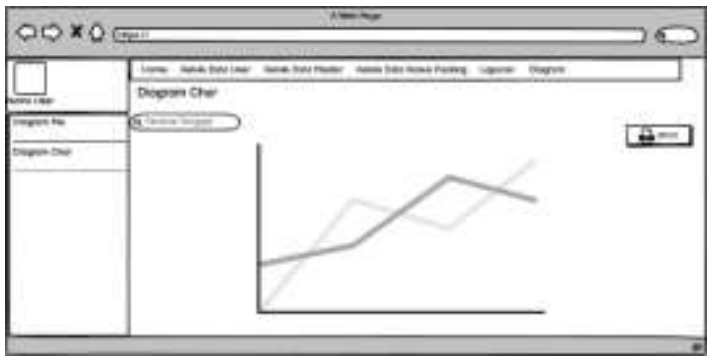

Gambar 20 Tampilan Diagram Char

\section{KESIMPULAN} adalah:

Kesimpulan dari penulisan karya ilmiah ini

1. Rancangan sistem informasi monitoring quality control dan defective produksi dibuat sebagai solusi untuk mengatasi kendala sistem yang berjalan saat ini pada PT Ultra Prima Abadi.

2. Rancangan sistem yang diusulkan dapat memberikan kemudahan bagi pimpinan untuk memonitoring quality control dan defective produksi.

\section{REFERENSI}

Irwan, \& Haryono, D. (2015). Pengendalian Kualitas Statistik (Pendekatan Teoritis dan Aplikatif). Bandung: Alfabeta.

Mudjahidin, \& Putra, N. D. (2010). Rancang Bangun Sistem Informasi Monitoring Perkembangan Proyek Berbasis Web Studi Kasus di Dinas Bina Marga dan Pemantusan. Jurnal Teknik Industri , 75-83.

DESTRIANA, Rachmat, et al. ANALISIS DAN PERANCANGAN SISTEM INFORMASI E-BISNIS MENGGUNAKAN SWOT ANALISIS PADA USAHA KECIL MENENGAH BERBASIS WEB ECOMMERCE. 2020.

Rahmayani, L., \& Haryanto. (2018). Rancang Bangun Aplikasi Monitoring Laporan Quality Control Dan Defective Produksi Sepatu Berbasis Web (Studi Pada Pt. Panarub Industry). JUTIS , 77-81.

Taufiq, R., Kasoni, D., \& Liesnaningsih. (2020). Rancang Bangun Sistem Informasi Pengolahan Nilai Siswa Berbasis Web pada SMK Putra Rifara Tangerang. Proceeding SENDIU 2020 , 394-401.

Taufiq, Rohmat. (2018). Pengantar Sistem Informasi.Jakarta. Mitra Wacana Media.

Taufiq, R., Magfiroh, D. A., Yusup, D., \& Yulianti, Y. (2020). Analisis dan Desain Sistem Informasi Pembayaran Sumbangan Pembinaan Pendidikan (SPP) di SMK Avicena Rajeg. Jurnal Teknologi Sistem Informasi dan Aplikasi, 3(1), 15-21. doi:10.32493/jtsi.v3i1.4308

Dunn, W,N (1994). Pengantar Analisis Kebijakan Publik. Yogyakarta. Gadjah Mada University Press

Yanuardi, Y., \& Destriana, R. (2020). PERANCANGAN SISTEM INFORMASI PENJUALAN ONLINE GAS DALAM STRATEGI E-BUSINESS MENGGUNAKAN ANALISIS SWOT. JIKA (Jurnal Informatika), 4(1), 1-6. 